Pedagogía y Saberes No. 49

Universidad Pedagógica Nacional

Facultad de Educación. 2018, pp. 95-113

\title{
Tendencias investigativas para pensar la relación entre las ciencias sociales escolares y la epistemología de las ciencias sociales en Colombia*
}

Artículo de investigación

Research Trends to Think about the Relationship between School Social Sciences and the Epistemology of Social Sciences in Colombia Tendências de pesquisa para pensar a relação entre as Ciências Sociais escolares e a epistemologia das Ciências Sociais na Colômbia

Para citar este artículo:

Martínez, N. (2018). Tendencias investigativas para pensar la relación entre las ciencias sociales escolares y la epistemología de las ciencias sociales en Colombia. Pedagogía y Saberes, 49, 95-113.

* Artículo derivado del proyecto de tesis doctoral inscrito en la línea Historia de la Educación, Pedagogía y Educación Comparada (HEPEC) del Doctorado Interinstitucional en Educación (DIE).

** Profesora de la Corporación Universitaria Minuto de Dios y de la Universidad Pedagógica Nacional. Estudiante de Doctorado Interinstitucional en Educación, sede Universidad Distrital Francisco José de Caldas. Investigadora de los grupos: Formación de Educadores y Ciudadanía, Paz y Desarrollo, Uniminuto.

Correo electrónico: nathaliamartinezm@gmail.com

Código ORCID: http://orcid.org/0000-0001-8918-3293 


\title{
Resumen
}

El artículo presenta la revisión bibliográfica realizada como base para la problematización y el desarrollo de una tesis doctoral que indaga sobre de la configuración de las ciencias sociales escolares durante el siglo xx y su relación con las epistemologías de las ciencias sociales. Esta muestra avances sobre las tendencias teórico-metodológicas en el campo de conocimiento de la historia de la educación y de la epistemología de las ciencias sociales, que permiten estudiar de manera compleja la configuración histórica de una disciplina escolar: las ciencias sociales en relación con las llamadas "ciencias de referencia" y con las epistemologías que circularon, se apropiaron y resignificaron en el transcurso del siglo Xx en Colombia. Además, evidencia una dispersión de temas frente a este objeto de estudio que fueron agrupados en tres tendencias o núcleos en este documento: historia de las disciplinas y de los saberes escolares, didáctica de las ciencias en relación con su estatus epistemológico y epistemología de las ciencias sociales.

\section{Palabras clave}

ciencias sociales escolares; epistemología de las ciencias sociales; historia de las disciplinas escolares; historia de los saberes escolares; Colombia

\begin{abstract}
This paper presents a bibliographic review made as a basis for the problematization and development of a doctoral thesis that investigates the configuration of social sciences in school in the $20^{\text {th }}$ century and its relationship with the epistemologies of social sciences. It reveals progress on the theoretical-methodological trends in the field of knowledge of the history of education and the epistemology of social sciences, which allow a more complex study of the historical configuration of a school subject: social sciences with regard to the so-called "reference sciences" and with the epistemologies that were circulated, appropriated and re-signified over the course of the $20^{\text {th }}$ century in Colombia. It also shows a scattering of issues regarding this object of study, which were grouped into three trends or cores in this document: history of school subjects and knowledge, science education related to their epistemological status and the epistemology of social sciences.
\end{abstract}

\section{Keywords}

social sciences in school; epistemology of social sciences; history of school subjects; history of school knowledge; Colombia

\section{Resumo}

El artículo apresenta a revisão bibliográfica realizada como base para a problematização e o desenvolvimento da tese de doutoramento que indaga sobre a configuração das Ciências Sociais escolares durante o século xx e sua relação com as epistemologias das ciências sociais. Esta amostra de avanços sobre as tendências teórico-metodológicas no campo de conhecimento da história da educação e da epistemologia das Ciências Sociais, que permitem estudar de forma complexa a configuração histórica da disciplina escolar: as Ciências Sociais em relação com as chamadas "Ciências de referência" e com as epistemologias que circularam, se apropriaram e ressignificaram o percurso do século xx na Colômbia. Além disso, evidencia-se uma dispersão de temas em face desse objetivo de estudo que forma agrupados em três tendências ou núcleos neste documento: história das disciplinas e os saberes escolares, didática das Ciências em relação com seu status epistemológico e epistemologia das Ciências Sociais.

\section{Palavras-chave}

ciências sociais escolares; epistemologia das ciências sociais; história das disciplinas; história dos conhecimentos escolares; Colômbia 


\section{Introducción}

El asunto de las ciencias sociales escolares y sus relaciones con las epistemologías de las ciencias sociales se puede concebir como un campo prolífico de estudio a pesar de que, como se muestra en este rastreo sobre la producción académica, poco se ha indagado al respecto. No obstante, se encuentran variedad de investigaciones sobre la conformación de las disciplinas escolares en contextos específicos a la luz del análisis del currículo, de la formación de maestros desde la emergencia de su campo profesional, de las prácticas pedagógicas o de los libros de texto; o sobre la conformación epistemológica de las disciplinas que constituyen las ciencias sociales desde el siglo XIX, incluyendo el ámbito de la didáctica, que se asume como disciplina científica en estas apuestas.

Siguiendo esta variedad de producción, la revisión bibliográfica se organizó en tres grandes tendencias investigativas o núcleos de problematización a partir de la cercanía con el objeto de estudio, que es uno de los resultados en términos de aportes analíticos que permitieron los trabajos reseñados. La primera, es la historia de las disciplinas y de los saberes escolares como núcleo investigativo por su articulación directa con la investigación, que se concibe como un programa emergente de investigación en Colombia y algunos países de Latinoamérica, fundamentado en los desarrollos que desde la década de 1980 tuvo este campo en Europa y en Estados Unidos. La segunda, la didáctica de las ciencias (ciencias sociales, ciencias naturales o matemáticas), como núcleo relacional, que se centra en el análisis de la epistemología de la didáctica del campo social, del conocimiento de los profesores sobre la disciplina escolar; asimismo en las relaciones entre el conocimiento científico, la epistemología de las ciencias y el conocimiento escolar o las disciplinas escolares. Por último, la historia de la ciencia asumida como núcleo correlacional, en la que se discute el estatuto epistemológico bien sea de distintas disciplinas sociales o de las ciencias sociales en su integralidad. Estas tres líneas se inscriben en el campo de conocimiento de la historia de la educación y de la epistemología de las ciencias sociales ${ }^{1}$.

1 La dispersión de temáticas y estudios abordados en esta revisión bibliográfica da cuenta de la dispersión misma de la que ha sido objeto en la producción académica el problema de estudio sobre la emergencia de las ciencias sociales escolares y su relación con la epistemología de las ciencias. De modo que las tres líneas, o núcleos, responden a la fragmentación que se optó para la búsqueda de literatura especializada entre trabajos que trataran la configuración de las ciencias sociales escolares, el asunto de la epistemología de las ciencias sociales y la didáctica de las ciencias sociales desde el referente epistemológico, debido a la escasez o nulidad de indagaciones que trataran los dos aspectos centrales de forma articulada.
Indagar por la manera como se ha investigado y lo que se ha investigado en dichos núcleos de problematización se considera la base tanto para la construcción del problema de tesis doctoral como para su desarrollo. Siguiendo a Jiménez y Torres (2006), la exploración de la producción bibliográfica existente sobre el tema de interés permite reconocer:

¿Cuáles disciplinas o campos de saber se han ocupado de lo que me interesa? ¿Cuáles han sido las problemáticas o aspectos sobre los que se ha centrado la investigación existente? ¿Cuáles enfoques o perspectivas teóricas han sido empleados para abordar la temática? ¿Cuáles enfoques y estrategias metodológicas se han utilizado? ¿Qué se sabe ya sobre lo que me interesa? ¿Cuáles aspectos o preguntas están aún por abordar? (p. 17).

De acuerdo con lo anterior, esta es una primera aproximación a la identificación de estos elementos necesarios en el desarrollo de una investigación que se inscribe en el campo de la historia de la educación y de la pedagogía. Dichas investigaciones ofrecen una muestra representativa de la producción académica que se ha realizado a escala nacional e internacional en relación con el problema, que muestran en algunos casos aportes teóricos, analíticos y metodológicos que proveen a la tesis doctoral, desde las cuales se plantean reflexiones epistemológicas de cada objeto de estudio, o en otros, las distancias de enfoques y de énfasis que se establecen con las diferentes perspectivas descritas.

En su mayoría los estudios reseñados son de formación doctoral o de nivel avanzado que se sistematizan en libros, algunos pocos capítulos o artículos de síntesis. Han sido producidos en Colombia, en países de Latinoamérica y Europa, y en Estados Unidos; además, cuentan con versión en castellano en su conjunto. Se producen desde la década de 1990 hasta mediados del 2000, pues es en ese periodo cuando se registra la aparición del tema como objeto de estudio, que sigue siendo explorado en la actualidad. En cada una se observa la constitución de líneas investigativas de distinto avance que dan cuenta de su grado de desarrollo, de la manera como ha sido abordado, de los enfoques teóricos y metodológicos utilizados para su estudio y de las categorías más recurrentes.

Se destaca, además, que en esta producción se localizaron cuatro estados del arte (uno contenido en una tesis doctoral) que permiten sintetizar los avances y los hallazgos del primer núcleo o tendencia, lo cual amplía la cantidad de documentos que

No obstante, como se verá a lo largo del texto, las tres líneas generan aportes relevantes a la tesis y justifican la singularidad del objeto de estudio. 
pudieran identificarse para explorar los aportes a esta investigación ${ }^{2}$.

Como hallazgo central en la búsqueda de trabajos que se ocuparan de la relación entre las ciencias sociales escolares y las epistemologías de las ciencias sociales se constata la dispersión de temas, que van desde aproximaciones socio-genéticas o históricas sobre la configuración de las disciplinas y de los saberes escolares, hasta propuestas para restituir el estatuto epistemológico de las didácticas de las ciencias (con especial énfasis en las ciencias sociales), o de las ciencias sociales como disciplinas científicas. Esta dispersión es resultado de la ausencia de estudios consolidados sobre tal relación, advertida por Álvarez (2007) un decenio atrás, pese a ser un punto central de discusión entre distintos actores e instituciones del ámbito educativo en el país, como el Ministerio de Educación Nacional, académicos de reconocida trayectoria, e incluso para docentes a quienes se les interroga de manera constante por sus prácticas pedagógicas.

Un ejemplo de ello es la afirmación que en agosto de 2014 realizó el licenciado en Filosofía y Letras Jorge Orlando Melo en el periódico El Tiempo, al reflexionar sobre la integración de las ciencias sociales escolares desde 1984 y la propuesta de lineamientos para las ciencias sociales del 2001, cuyo modelo está centrado en un enfoque problémico: "Esta rimbombante solución de las dificultades de enseñar juntas las ciencias sociales no mejoró la situación, pues exigía maestros muy preparados, verdaderos teóricos en la epistemología de las ciencias sociales" (Melo, 2014, párr. 3), lo cual es indicio, para este académico, de una supuesta desaparición de la historia escolar. Este señalamiento da cuenta de la supremacía que se promueve de manera frecuente en el escenario académico del conocimiento científico o de la epistemología de las ciencias sobre el saber pedagógico.

Por tanto, las vías alternativas para afrontar problemas en la enseñanza y en el aprendizaje de las disciplinas escolares oscilan entre recurrir a propuestas que adapten los conocimientos académicos

2 La clasificación establecida por el Departamento Administrativo de Ciencia, Tecnología e Innovación-Colciencias en el marco del Sistema Nacional de Indexación de Revistas Científicas de Ciencia (Publindex), y que ha sido tomada como referencia para artículos de revisión en el ámbito académico, señala el uso de por lo menos 50 referencias en una revisión bibliográfica. Siguiendo este parámetro, en este trabajo acopiamos y tematizamos 70 referencias, de las cuales se seleccionaron 34 que finalmente tenían algún grado de cercanía con el problema de investigación. Entre ellas se encuentran 4 estados del arte, que permiten ampliar el margen de bibliografía requerida para delimitar tendencias teóricas, metodológicas y analíticas como función principal de este tipo de exploración. en contenidos de enseñanza, como la transposición didáctica, o fortalecer disciplinar y epistemológicamente la formación de maestros. Muestra de ello es la afirmación que hace Darío Campos, profesor de la Universidad Nacional, en la revista Semana sobre el reto que significa la creación de la asignatura de Ciencias Sociales debido a la necesidad de profesores con un conocimiento profundo de estas disciplinas (Semana, 2012, párr. 4). Así también lo señala el historiador Heraclio Bonilla, quien señala que

... además de la mala formación de los maestros, los
textos actuales están desactualizados y evidencian
una separación entre lo que se publica y descubre
en la academia y lo que se enseña en las aulas esco-
lares, que es una historia conservadora, clásica, del
siglo antepasado. (Semana, 2012, párr. 6).

Pero también en otra orilla se convoca a reforzar la pedagogía, muchas veces sin articulación ni diálogo con las discusiones académicas de los campos de saber o de las disciplinas del ámbito científico. Esto, en palabras de Gerardo Roa Ogando, docente de la Universidad Autónoma de Santo Domingo, conduce a un pedagogismo o exceso de pedagogía, lo cual implica

... reducirlo todo a pura forma, al grado de pensar que con algunos trucos tecnológicos se puede ser capaz de enseñar cualquier contenido, soslayando la lectura crítica, profunda y sistemática de saberes humanísticos, más allá de las fronteras del área estrictamente disciplinaria. (Roa, 2017, párr. 4).

Esta dispersión temática permite justificar la singularidad del objeto de estudio sustentada en tres tendencias investigativas que marcan la organización de las fuentes en esta revisión bibliográfica como se ha venido mencionando (véase la figura 1). De esta manera, la búsqueda de la producción académica sobre el tema se focalizó tanto en la configuración de las disciplinas escolares como en el asunto epistemológico de las disciplinas académicas de referencia y de la didáctica por considerarla, en los mismos documentos trabajados, la disciplina que tiene como objeto de estudio la enseñanza. Esto permitió identificar los nodos de los dos elementos centrales del problema de investigación: las ciencias sociales escolares y las epistemologías de las ciencias sociales. En la tabla 1 se compendian los distintos trabajos localizados en las tres tendencias investigativas o núcleos de problematización, se describe el nombre de cada una, los autores y las autoras de referencia, el año de publicación y el tipo de documento. 


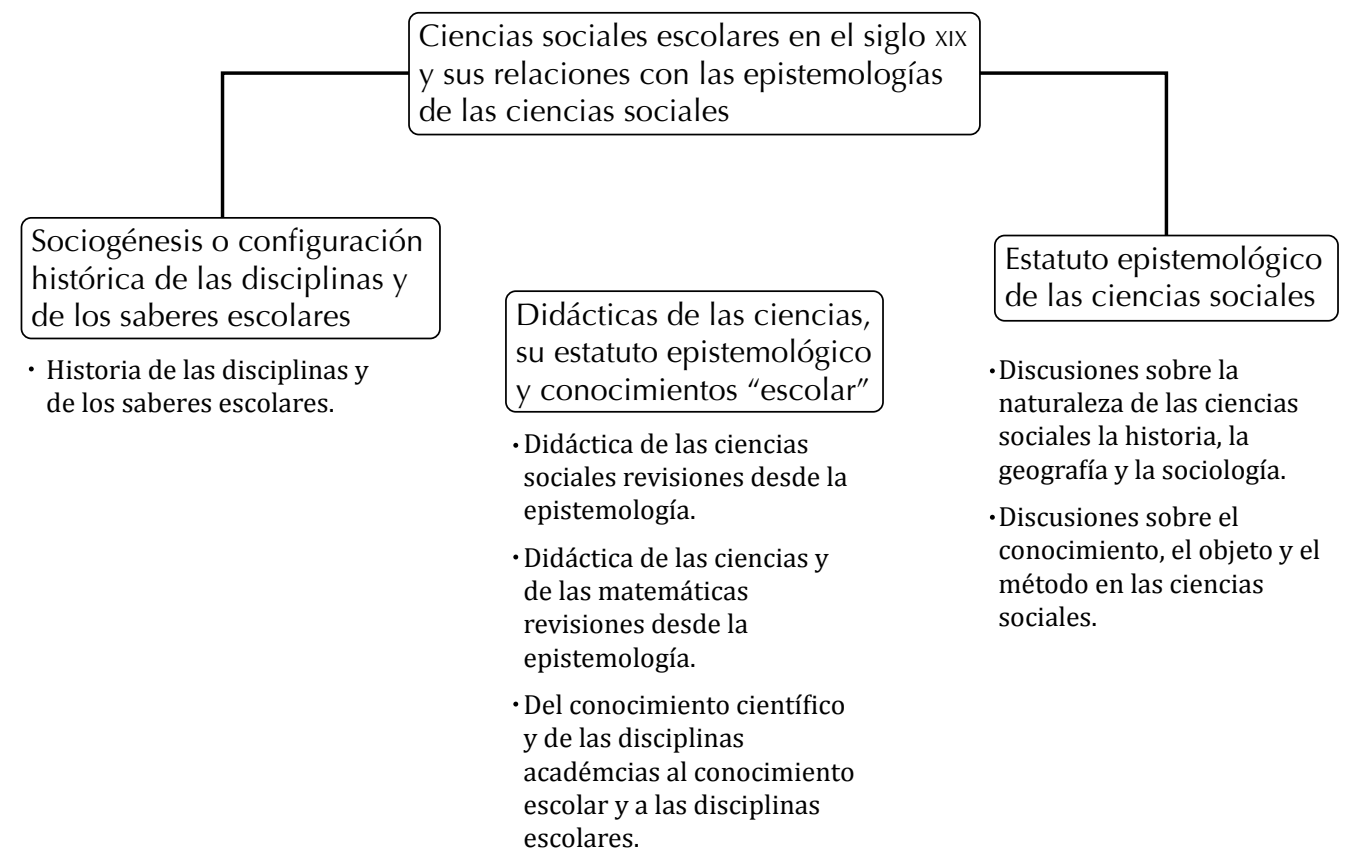

Figura 1. Tendencias investigativas en la revisión bibliográfica

Fuente: elaboración propia

Tabla 1. Compilación de estudios de la revisión bibliográfica

\begin{tabular}{|c|c|c|c|c|c|}
\hline & Nombre de la investigación & Autor(es) & Año & $\begin{array}{c}\text { Tipo de } \\
\text { documento }\end{array}$ & $\begin{array}{c}\text { Tendencias investigativas } \\
\text { o núcleos de } \\
\text { problematización }\end{array}$ \\
\hline 1 & $\begin{array}{l}\text { Sociogénesis de una } \\
\text { disciplina escolar: la historia }\end{array}$ & Raimundo Cuesta & 1997 & $\begin{array}{l}\text { Libro resultado } \\
\text { de tesis doctoral }\end{array}$ & \multirow{8}{*}{$\begin{array}{l}\text { Historia de las disciplinas } \\
\text { y de los saberes escolares }\end{array}$} \\
\hline 2 & $\begin{array}{l}\text { La genealogía, historia del } \\
\text { presente y didáctica crítica }\end{array}$ & $\begin{array}{l}\text { Raimundo Cuesta, } \\
\text { Juan Mainer, } \\
\text { Julio Mateos }\end{array}$ & 2008 & $\begin{array}{l}\text { Capítulo resultado } \\
\text { de investigación }\end{array}$ & \\
\hline 3 & $\begin{array}{l}\text { La historia de las } \\
\text { disciplinas escolares }\end{array}$ & Antonio Viñao & 2006 & $\begin{array}{l}\text { Artículo resultado } \\
\text { de investigación }\end{array}$ & \\
\hline 4 & $\begin{array}{l}\text { La historia de las } \\
\text { disciplinas escolares. } \\
\text { Génesis y problemas } \\
\text { de un joven campo de } \\
\text { investigación. El interés } \\
\text { del proyecto Nebraska } \\
\text { Fedicaria en el tema }\end{array}$ & Juan Mainer Baqué & 2010 & Ponencia & \\
\hline 5 & $\begin{array}{l}\text { La forja de un campo } \\
\text { profesional. Pedagogía y } \\
\text { didáctica de las ciencias } \\
\text { sociales en España } \\
\end{array}$ & Juan Mainer Baqué & 2009 & $\begin{array}{l}\text { Libro resultado } \\
\text { de tesis doctoral }\end{array}$ & \\
\hline 6 & $\begin{array}{l}\text { Pensar críticamente la } \\
\text { educación escolar }\end{array}$ & $\begin{array}{l}\text { Juan Mainer } \\
\text { Baqué (coord.) }\end{array}$ & 2008 & $\begin{array}{l}\text { Libro resultado } \\
\text { de investigación }\end{array}$ & \\
\hline 7 & $\begin{array}{l}\text { Sociogénesis de la didáctica } \\
\text { de las ciencias sociales. } \\
\text { Tradición discursiva y campo } \\
\text { profesional (1900-1970) }\end{array}$ & Juan Mainer Baqué & 2007 & Tesis doctoral & \\
\hline 8 & $\begin{array}{l}\text { La construcción del } \\
\text { código pedagógico del } \\
\text { entorno. Genealogía } \\
\text { de un saber escolar }\end{array}$ & Julio Mateos & 2008 & $\begin{array}{l}\text { Libro resultado } \\
\text { de tesis doctoral }\end{array}$ & \\
\hline
\end{tabular}




\begin{tabular}{|c|c|c|c|c|c|}
\hline & Nombre de la investigación & Autor(es) & Año & $\begin{array}{c}\text { Tipo de } \\
\text { documento }\end{array}$ & $\begin{array}{c}\text { Tendencias investigativas } \\
\text { o núcleos de } \\
\text { problematización }\end{array}$ \\
\hline 9 & $\begin{array}{l}\text { Formación de nación } \\
\text { y educación (2010) }\end{array}$ & $\begin{array}{l}\text { Alejandro } \\
\text { Álvarez Gallego }\end{array}$ & 2010 & $\begin{array}{l}\text { Libro resultado } \\
\text { de investigación } \\
\text { doctoral }\end{array}$ & \multirow{5}{*}{$\begin{array}{l}\text { Historia de las disciplinas } \\
\text { y de los saberes escolares }\end{array}$} \\
\hline 10 & $\begin{array}{l}\text { Las ciencias sociales } \\
\text { en el currículo escolar: } \\
\text { Colombia 1930-1960 }\end{array}$ & $\begin{array}{l}\text { Alejandro } \\
\text { Álvarez Gallego }\end{array}$ & 2007 & Tesis doctoral & \\
\hline 11 & $\begin{array}{l}\text { Investigar históricamente } \\
\text { las disciplinas y los saberes } \\
\text { escolares: el caso de la } \\
\text { enseñanza de las ciencias } \\
\text { sociales en Colombia }\end{array}$ & $\begin{array}{l}\text { Orlando Silva } \\
\text { Briceño }\end{array}$ & 2018 & $\begin{array}{l}\text { Artículo resultado } \\
\text { de tesis doctoral }\end{array}$ & \\
\hline 12 & $\begin{array}{l}\text { La configuración y } \\
\text { consolidación de la } \\
\text { enseñanza de las ciencias } \\
\text { sociales como campo de } \\
\text { saber-poder 1970-1994 } \\
\end{array}$ & $\begin{array}{l}\text { Orlando Silva } \\
\text { Briceño }\end{array}$ & 2017 & Tesis doctoral & \\
\hline 13 & $\begin{array}{l}\text { Historia de las disciplinas } \\
\text { y de los saberes escolares: } \\
\text { un campo de investigación } \\
\text { emergente en Colombia }\end{array}$ & $\begin{array}{l}\text { Orlando Silva } \\
\text { Briceño }\end{array}$ & 2012 & $\begin{array}{l}\text { Ponencia resultado } \\
\text { de tesis doctoral }\end{array}$ & \\
\hline 14 & $\begin{array}{l}\text { Didáctica de las ciencias } \\
\text { sociales: aportes } \\
\text { y reflexiones }\end{array}$ & $\begin{array}{l}\text { Silvia Alderoqui, } \\
\text { Beatriz Aisenberg } \\
\text { (coord.) } \\
\end{array}$ & 1994 & $\begin{array}{l}\text { Libro resultado } \\
\text { de investigación }\end{array}$ & \multirow{7}{*}{$\begin{array}{l}\text { Didáctica de las } \\
\text { ciencias: epistemología } \\
\text { de la didáctica de las } \\
\text { ciencias sociales }\end{array}$} \\
\hline 15 & $\begin{array}{l}\text { Epistemología de la didáctica } \\
\text { de las ciencias sociales }\end{array}$ & Alicia Camilloni & 1995 & $\begin{array}{l}\text { Artículo resultado } \\
\text { de investigación }\end{array}$ & \\
\hline 16 & $\begin{array}{l}\text { Líneas de investigación } \\
\text { en didáctica de las } \\
\text { ciencias sociales }\end{array}$ & Joan Pagès Blanch & 1997 & $\begin{array}{l}\text { Artículo de } \\
\text { reflexión basado en } \\
\text { estudios anteriores }\end{array}$ & \\
\hline 17 & $\begin{array}{l}\text { Las finalidades de la } \\
\text { educación social }\end{array}$ & Pilar Benejam & 1997 & $\begin{array}{l}\text { Artículo resultado } \\
\text { de investigación }\end{array}$ & \\
\hline 18 & $\begin{array}{l}\text { Enseñar y aprender ciencias } \\
\text { sociales, geografía e historia } \\
\text { en la educación secundaria }\end{array}$ & $\begin{array}{l}\text { Pilar Benejam } \\
\text { y Joan Pagès } \\
\text { Blanch (coord.) }\end{array}$ & 1997 & $\begin{array}{l}\text { Libro resultado } \\
\text { de investigación } \\
\text { y de reflexión } \\
\end{array}$ & \\
\hline 19 & $\begin{array}{l}\text { Didáctica de las ciencias } \\
\text { sociales: ¿desde qué teorías } \\
\text { estudiamos la enseñanza? }\end{array}$ & Beatriz Aisenberg & 1998 & $\begin{array}{l}\text { Artículo resultado } \\
\text { de investigación }\end{array}$ & \\
\hline 20 & $\begin{array}{l}\text { Didáctica de las ciencias } \\
\text { sociales II: teorías } \\
\text { con prácticas }\end{array}$ & $\begin{array}{l}\text { Silvia Alderoqui y } \\
\text { Beatriz Aisenberg } \\
\text { (coord.) } \\
\end{array}$ & 1998 & $\begin{array}{l}\text { Libro resultado } \\
\text { de investigación }\end{array}$ & \\
\hline 21 & $\begin{array}{l}\text { Las propuestas curriculares } \\
\text { sobre el conocimiento } \\
\text { escolar en el área de } \\
\text { conocimiento del medio: } \\
\text { dos estudios de caso en } \\
\text { profesores de primaria }\end{array}$ & $\begin{array}{l}\text { Carmen Alicia } \\
\text { Martínez }\end{array}$ & 2000 & Tesis doctoral & \multirow{3}{*}{$\begin{array}{l}\text { Didáctica de las } \\
\text { ciencias: epistemología } \\
\text { de la didáctica de las } \\
\text { ciencias sociales }\end{array}$} \\
\hline 22 & $\begin{array}{l}\text { La investigación sobre } \\
\text { el conocimiento del } \\
\text { profesor: algunos } \\
\text { aspectos conceptuales } \\
\text { y metodológicos }\end{array}$ & $\begin{array}{l}\text { Carmen Alicia } \\
\text { Martínez y Ana } \\
\text { Rivero García }\end{array}$ & 2012 & $\begin{array}{l}\text { Capítulo resultado } \\
\text { de investigación }\end{array}$ & \\
\hline 23 & $\begin{array}{l}\text { Análisis de la trasposición } \\
\text { didáctica del concepto de } \\
\text { biodiversidad. Orientaciones } \\
\text { para su enseñanza }\end{array}$ & $\begin{array}{l}\text { Gonzalo Bermúdez } \\
\text { y Ana Lía de Longhi }\end{array}$ & 2012 & $\begin{array}{l}\text { Capítulo resultado } \\
\text { de investigación }\end{array}$ & \\
\hline
\end{tabular}




\begin{tabular}{|c|c|c|c|c|c|}
\hline & Nombre de la investigación & Autor(es) & Año & $\begin{array}{c}\text { Tipo de } \\
\text { documento }\end{array}$ & $\begin{array}{c}\text { Tendencias investigativas } \\
\text { o núcleos de } \\
\text { problematización }\end{array}$ \\
\hline 24 & $\begin{array}{l}\text { Del álgebra al cálculo: } \\
\text { ¿transición o ruptura? } \\
\text { Notas para una reflexión } \\
\text { epistemológica y didáctica }\end{array}$ & $\begin{array}{l}\text { Gloria Inés Neira } \\
\text { Sanabria }\end{array}$ & 2012 & $\begin{array}{l}\text { Capítulo resultado } \\
\text { de investigación }\end{array}$ & \multirow{3}{*}{$\begin{array}{l}\text { Didáctica de las } \\
\text { ciencias: epistemología } \\
\text { de la didáctica de las } \\
\text { ciencias sociales }\end{array}$} \\
\hline 25 & $\begin{array}{l}\text { El hombre de la calle, el } \\
\text { científico y el alumno: ¿un } \\
\text { solo constructivismo o tres? }\end{array}$ & María José Rodrigo & 1994 & $\begin{array}{l}\text { Artículo de } \\
\text { reflexión basado en } \\
\text { estudios anteriores }\end{array}$ & \\
\hline 26 & $\begin{array}{l}\text { Relaciones entre } \\
\text { conocimiento escolar y } \\
\text { conocimiento científico }\end{array}$ & Daniel Gil Pérez & 1994 & $\begin{array}{l}\text { Artículo de } \\
\text { reflexión basado en } \\
\text { estudios anteriores }\end{array}$ & \\
\hline 27 & Historia y verdad & Adam Schaff & 1974 & $\begin{array}{l}\text { Libro resultado } \\
\text { de investigación }\end{array}$ & \multirow{8}{*}{ Historia de la ciencia } \\
\hline 28 & $\begin{array}{l}\text { La investigación histórica: } \\
\text { teoría y método }\end{array}$ & Julio Aróstegui & 1995 & $\begin{array}{l}\text { Libro resultado } \\
\text { de investigación }\end{array}$ & \\
\hline 29 & $\begin{array}{l}\text { Los horizontes de } \\
\text { la geografía }\end{array}$ & $\begin{array}{l}\text { José Ortega } \\
\text { Valcárcel } \\
\end{array}$ & 2000 & $\begin{array}{l}\text { Libro resultado } \\
\text { de investigación }\end{array}$ & \\
\hline 30 & $\begin{array}{l}\text { Epistemología y ciencias } \\
\text { sociales (textos escritos } \\
\text { entre } 1950 \text { y } 1960 \text { ) }\end{array}$ & Theodor Adorno & 2001 & $\begin{array}{l}\text { Libro resultado } \\
\text { de investigación }\end{array}$ & \\
\hline 31 & Lógica de las ciencias sociales & Jürgen Habermas & 1990 & $\begin{array}{l}\text { Libro resultado } \\
\text { de investigación }\end{array}$ & \\
\hline 32 & $\begin{array}{l}\text { Historia y filosofía de } \\
\text { las ciencias sociales }\end{array}$ & Scott Gordon & 1995 & $\begin{array}{l}\text { Libro resultado } \\
\text { de investigación }\end{array}$ & \\
\hline 33 & $\begin{array}{l}\text { Prácticas científicas } \\
\text { y procesos sociales. } \\
\text { Una genealogía de las } \\
\text { relaciones entre ciencias } \\
\text { naturales, ciencias } \\
\text { sociales y tecnologías }\end{array}$ & Susana Murillo & 2012 & $\begin{array}{l}\text { Libro resultado } \\
\text { de investigación }\end{array}$ & \\
\hline 34 & $\begin{array}{l}\text { Epistemología de las } \\
\text { ciencias sociales }\end{array}$ & $\begin{array}{l}\text { Héctor Palma y } \\
\text { Rubén Pardo }\end{array}$ & 2012 & $\begin{array}{l}\text { Libro resultado } \\
\text { de investigación }\end{array}$ & \\
\hline
\end{tabular}

Fuente: elaboración propia

\section{Sociogénesis o configuración histórica de las disciplinas y de los saberes escolares}

La primera línea de investigación propuesta en esta revisión hace referencia a la historia de las disciplinas y de los saberes escolares tanto en Colombia como en el plano internacional. En el país, su centro han sido las ciencias sociales escolares; en ella se encuentran estudios recientes que empiezan a constituirlo como un ámbito investigativo de importancia para la historia de la educación del país antes inexistente. En esta línea, dichos trabajos coinciden en ubicarse en una genealogía del presente, enmarcada en la historia social del currículo o en la historia de las disciplinas escolares y de los saberes escolares (para el caso colombiano), para analizar el conocimiento social que se genera en el ámbito escolar. Entre ellos encontramos los de Cuesta (1997, 2008), Viñao (2006), Mateos (2008), Mainer (2007, 2009, 2010), Álvarez (2007, 2010) y Silva $(2012,2017,2018)$.

De ello se deriva la necesidad de la mirada histórica para la descripción y la comprensión de los fenómenos sociales, así como lo imperioso de reconocer que el fundamento de la reproducción y el cambio de las instituciones sociales se cimienta en la interacción dialéctica entre la acción de los sujetos y las estructuras o los fenómenos sociales, de allí que se proponga una mirada macro y micro-histórica de los objetos de estudio. En esta línea, desde el estudio sociogenético de la historia escolar o del área del conocimiento del medio ${ }^{3}$ se asume la tarea de adentrarse en la historia de una disciplina escolar, bien sea

3 Conocimiento escolar que tomó forma como asignatura en España en el decenio de 1990 con el nombre de "Conocimiento del medio natural, social y cultural", que no cuenta con referente en ninguna disciplina académica. 
aquella que presenta como referente una disciplina académica o aquel conocimiento escolar regulado, normalizado y pedagogizado. Estas investigaciones también se han encargado de indagar por la historia de la constitución de disciplinas académicas como la didáctica de las ciencias sociales ${ }^{4}$ y su consecuente proceso de profesionalización durante el periodo de 1900 a 1970 en España, utilizando como referente temporal la larga duración mediante la delimitación de los modos de educación y como referente epistémico-metodológico la perspectiva de la didáctica crítico-genealógica, entendida como un proyecto que propende por la construcción de una didáctica soportada en distintas tradiciones de pensamiento crítico (Cuesta, Mainer y Mateos, 2009), cuyo propósito reside en la necesidad de problematizar y de asumir genealógicamente el campo de la didáctica, pero también el de los cuerpos docentes.

En el caso colombiano, estos estudios se han centrado en las condiciones de aparición de la enseñanza de las ciencias sociales en la escuela a inicios del siglo $\mathrm{xx}$ y el proceso de consolidación que se visibiliza desde mediados de la década de 1980 hasta 1990, aduciendo a los hitos de ruptura que se presentaron en este periodo y no como un asunto de progresión. El acento se puso, por un lado, en las condiciones de posibilidad del nacionalismo en el país, a partir de las relaciones de poder que se fueron configurando, los regímenes de verdad que se instituyeron a partir de tres inquietudes: el pasado, el pueblo y el territorio, que se convirtieron en disciplinas escolares, y la aparición de instituciones como la escuela, que se transformó un espacio de disputa ideológica, profesional y política que permite su justificación. Esto muestra un aporte valioso a la historia del nacionalismo, a la historia de la pedagogía y a la historia de las ciencias sociales, por cuanto se considera que el surgimiento de las disciplinas y de los saberes escolares en sentido moderno se fundamenta en los Estados-nación, que instauran y legitiman las materias curriculares y la historia cultural que influye considerablemente en la estructuración de clases de las sociedades capitalistas.

Por otro lado, se enfatiza en el proceso mismo de constitución y consolidación de la enseñanza de las ciencias sociales como campo de saber-poder en el país, a través de

- Su producción en la historiografía de la educación en Colombia.

4 Esto es singular en comparación con la experiencia de Colombia, en donde la didáctica de las ciencias sociales alcanzó el lugar de discurso en el ámbito educativo, como soporte de los desarrollos en pedagogía, pero no pasó por un proceso de disciplinarización, institucionalización y profesionalización.
- Los agenciamientos que se expresan en las reformas y las políticas educativas.

- Aproximaciones al campo profesional de la educación y de la producción discursiva en el campo intelectual sobre las ciencias sociales escolares.

Una de las contribuciones clave tanto a este programa de investigación como a la tesis misma reside en la matriz analítica de niveles de agenciamiento (estratégico, maquínico y áulico), que permite distinguir lógicas y procedimientos múltiples de configuración de los acontecimientos historiados a partir de la categoría deleuziana de estratos, cuya delimitación temporal se enmarcaría en el modo de instrucción civilizatorio y en el modo de educación desarrollista.

Todas ellas presentan una periodización que corresponde a los propios procesos educativos y socioculturales que son objeto de estudio, y no a los periodos presidenciales o políticos, aunque se puede establecer vínculos con estos. De igual manera, se aproximan al estudio histórico desde el enfoque genealógico-arqueológico de Foucault o desde algunos de los postulados de Bourdieu, Weber o Bernstein; pero, sobre todo, desde la historia del currículum y las disciplinas escolares desarrollada desde la década de 1980 en Francia, España e Inglaterra.

Son varios los aportes de estas investigaciones a la tesis doctoral. En primer lugar, se perfila la historia de las disciplinas y de los saberes escolares como un campo de investigación que se encuentra en proceso de consolidación, lo que le brinda el marco de referencia analítico, conceptual y metodológico necesario para la indagación. En segundo lugar, y articulado a lo anterior, la delimitación del problema de investigación se orientó desde el sustento conceptual de la historia del currículum y las disciplinas escolares, a partir de los autores y de las perspectivas antes enunciados. Así, se tomaron las propuestas de autores como Popkewitz (1987), quien enfatiza en las relaciones de poder que constituyen la naturaleza del conocimiento escolar y llama la atención sobre el proceso de alquimia producido entre el saber académico y las disciplinas escolares (asunto muy distinto a la mera transposición); como Chervel (1991), quien conceptualiza el conocimiento escolar como producción particular de las culturas escolares; como Goodson (1991, 1995, 2003), cercano a la propuesta de Chervel, quien plantea que el conocimiento escolar es producto de las dinámicas sociales e históricas y de las relaciones de poder que intervienen en el currículo, y como Viñao (2006, 2009), quien propone un vínculo entre la historia de las disciplinas escolares y la historia del proceso de profesionalización de docentes. 
En tercer lugar, por su carácter histórico presentan una periodización que corresponde a la configuración particular de los fenómenos educativos y socioculturales que son objeto de estudio. Esto marca una distancia con la mayoría de tendencias históricas recurrentes sobre educación dentro y fuera del país, que se adhieren a los procesos político-administrativos como determinantes de lo educativo, sin definir relaciones ni inquirir otros aspectos o dinámicas.

En cuarto lugar, se proponen categorías teóricas y metodológicas desde las cuales se realizó el proceso de recolección de la información y se organizó esta tesis. Aparece entonces la categoría analítica de código disciplinar, definida como

\section{... el conjunto de ideas, valores, suposiciones y ru- tinas, que legitiman la función educativa atribuida a la Historia y que regulan el orden de la práctica de su enseñanza [...] En suma, el elenco de ideas, discursos y prácticas dominantes en la enseñanza de las asignaturas dentro del marco escolar. El có- digo disciplinar alberga, pues, las especulaciones y retóricas discursivas sobre su valor educativo, los contenidos de enseñanza y los arquetipos de la práctica docente, que se suceden en el tiempo y que se consideran, dentro de la cultura, valiosos y legítimos. (Cuesta, 1997, p. 33).}

Los códigos disciplinares se inscriben en una tradición social de larga duración que se articula al proceso de los modos de educación, que permiten romper la lógica lineal al indagar las dinámicas sociales, culturales y económicas generadas por los diversos regímenes políticos. Así, para estos estudios la enseñanza de las disciplinas escolares se puede valorar como recurrencia y como transformación para revelar las discontinuidades en el ritmo de los cambios entre los discursos y las prácticas, cuya definición epistemológica provee una clave de análisis en el trabajo con la documentación. Otra serie de categorías que surgen en las investigaciones reseñadas en esta tendencia como "cultura escolar", campo profesional o "gramática básica de la instrucción" son retomadas tanto en la delimitación teórica como en el proceso analítico de las fuentes en el documento de tesis.

En síntesis, en esta tendencia el énfasis se pone en la dimensión socio-histórica, en la singularidad de las reglas de producción, en la autonomía relativa con respecto a las ciencias de referencia y en la estabilidad del conocimiento histórico producido en el ámbito escolar. De allí que la categoría de ciencias sociales escolares $^{5}$, que será resultado de la tesis doctoral,

5 De manera preliminar, la categoría de ciencias sociales escolares, resultado de la revisión bibliográfica, se concibe en esta tesis doctoral como aquel saber producido en la escuela retome estas claves teóricas para su conceptualización, siendo esta construcción conceptual uno de los aportes centrales debido a su vaga y dispersa definición.

\section{Didácticas de las ciencias, su estatuto epistemológico y el conocimiento escolar}

En esta segunda tendencia o núcleo se ubican tres corrientes de trabajo: la primera, centra su exploración en la epistemología de la didáctica de las ciencias sociales con estudios como los de Camilloni (1995), Alderoqui y Aisenberg (1994; 1998), Benejam (1997), Pagès (1997) y Aisenberg (1998), entre otros. La segunda, trabaja en el ámbito de la didáctica de las ciencias; en ella se ubican las propuestas de Martínez y Rivero (2012), Bermúdez y De Longuí (2012) y Neira (2012). La tercera, aborda el vínculo entre el conocimiento científico a través de las disciplinas académicas y el conocimiento escolar expresado en las disciplinas escolares; en ella se enmarcan los trabajos de Rodrigo (1994) y Gil (1994). Esta agrupación obedece a la proximidad de sus objetos de estudio y de sus preguntas de investigación, aun desde demarcaciones distintas, a la cercanía en algunos planteamientos a partir de las posturas teóricas en las que se inscriben y a los propósitos éticos implícitos en cada una. Al final de la presentación de las tres corrientes se realizará una lectura crítica de este núcleo en función de los presupuestos de la tesis.

\section{Didáctica de las ciencias sociales: revisiones desde la epistemología}

En esta revisión bibliográfica se advierte que los países con mayor producción sobre la epistemología de la didáctica de las ciencias sociales son Argentina y España, en cabeza de investigaciones o programas liderados principalmente por académicas, con una abundante producción en el decenio de 1990. Por tanto, se toman las publicaciones que abordan esa relación directa entre la didáctica y la epistemología en el ámbito social.

Los problemas estudiados se delimitan alrededor del análisis del estatus epistemológico de la didáctica de las ciencias sociales, de las tradiciones epistemológicas en el ámbito científico y en el campo de la enseñanza de las ciencias sociales para el siglo Xx, y

y cuya función principal radica en la escuela, convertido en materia de enseñanza. Asimismo, se entiende como el saber producido en un régimen amplio del discurso sobre la enseñanza y lo que se debe enseñar, como el caso de las políticas y las reformas educativas. Esta categoría será ampliada en el documento final de la tesis. 
de los marcos teóricos utilizados en la didáctica de las ciencias sociales, que asumen la enseñanza como su objeto de estudio.

Para abordar el primer problema se proponen preguntas como: ¿Qué tipo de conocimiento es el conocimiento didáctico? ¿Cuál es su relación con otras disciplinas, sean del campo pedagógico o no? ¿Qué relación se establece entre el discurso didáctico y la práctica pedagógica?, entre otras, que van siendo tratadas a partir de la lectura crítica de diversas corrientes científicas en lo social para desentrañar el sentido o la concepción de didáctica que estas promueven. Con base en ello, la apuesta reside en conceptualizar la didáctica como una disciplina y un constructo teórico sobre la enseñanza.

El segundo problema de los estudios ubicados en esta corriente de trabajo, que hace referencia a las tradiciones epistemológicas en el ámbito científico, se soporta en las preguntas ¿Para qué enseñar ciencias sociales? y ¿Qué enseñar de ciencias sociales?, que indagan acerca de los propósitos de lo educativo en diferentes perspectivas teóricas. De acuerdo con esto, estos dos problemas se abordan mediante un balance de líneas de pensamiento que han incidido en discusiones acerca de la enseñanza de las ciencias sociales (de acuerdo a cada problema se hacen énfasis específicos), que van desde las concepciones positivista del siglo xx (Capel, 1987; Chorley y Haggett, 1971 y Walford, Bale y Graves, 1973) y neopositivista de Moore (1980) o Hirst (1982), hasta la teoría crítica de la Escuela de Frankfurt, así como la tradición humanista o reconceptualista propia de la década de 1960 , que se cimienta en esta, para encontrar puntos de divergencia entre ellas. También se menciona la llamada postura posmoderna, cuya aparición se ubica en los años ochenta.

Esto muestra que el núcleo común en dichas propuestas reposa en el análisis del estatus epistemológico de la didáctica de las ciencias sociales desde la discusión con el paradigma positivista hasta la perspectiva crítica de la ciencia. Igualmente, en estas se observa como rasgo compartido la elaboración de balances amplios de las principales corrientes o tradiciones epistemológicas que han influido en las concepciones sobre la enseñanza de las ciencias sociales en la actualidad desde una composición ensayística.

Esta es una contribución importante para la tesis al avanzar en el reconocimiento de los objetos de estudio que les son propios, de las discusiones centrales que las precisan, de los autores representativos, y aproximarse a la caracterización de dichas corrientes, lo cual facilita el trabajo con las fuentes primarias. Se tiene en cuenta este aporte a pesar de que el enfoque y el programa en que se enmarca la tesis se distancian de los encuadres de estas investigaciones.

Finalmente, uno de los mayores aportes de esta corriente es el análisis que ofrecen sobre la naturaleza del conocimiento didáctico ${ }^{6}$, así como las fuentes y los marcos teóricos que orientan el análisis del saber y la construcción de propuestas en este campo. Desde allí se problematizan aspectos como los efectos del estudio de un objeto de conocimiento a la luz de marcos teóricos que no fueron construidos para este y podrían llevar al "aplicacionismo disciplinar", las condiciones de su producción, la construcción o reconstrucción de los contenidos escolares por parte de los alumnos y las condiciones de la comunicación de los contenidos o enseñanza.

\section{Didáctica de las ciencias y de las matemáticas: revisiones desde la epistemología en el DIE ${ }^{7}$}

Esta segunda corriente de trabajo inscrita en el núcleo de la didáctica agrupa tres textos publicados por el Doctorado Interinstitucional en Educación-UD que forman parte de la colección Énfasis. En ellos se pregunta por el conocimiento didáctico y su relación con el conocimiento científico; al igual que por el conocimiento de los docentes acerca del conocimiento escolar a través de la pesquisa de contenidos y las prácticas escolares, estas dos desde reflexiones en torno a la epistemología del conocimiento didáctico. Por último, se encuentran los obstáculos epistemológicos que pueden observarse en las Prácticas Escolares Universitarias.

Estos objetos de estudio proponen cuestiones novedosas para el campo de indagación de la didáctica, algunas de las cuales se enmarcan en una línea investigativa de carácter nacional e internacional sobre la enseñanza de las ciencias y la formación de profesores, y del proyecto Investigación y Renovación Escolar. Desde este último ha sido posible rastrear cómo se produce conocimiento didáctico, cuáles son los criterios de validez y cuál es su naturaleza,

6 Estos estudios señalan tres interpretaciones vigentes sobre la naturaleza de este tipo de conocimiento: la didáctica como una teoría práctica, las didácticas específicas como disciplinas científicas que se nutren de investigaciones empíricas sobre su objeto de estudio (la enseñanza) y la didáctica como el cúmulo de reflexiones soportadas en distintas ciencias (véase Aisenberg, 1998).

7 Siguiendo a Foucault (1993), las tres dimensiones que conformarían la episteme moderna serían: las ciencias matemáticas y físicas, por un lado, las ciencias de la vida, del lenguaje, de la producción y distribución de las riquezas por el otro y la reflexión filosófica. Esto sustenta el reconocimiento de las diferencias epistemológicas entre las ciencias naturales y las matemáticas (pp. 336-337). 
lo cual hace referencia a la epistemología de este conocimiento.

Por otro lado, el interés por analizar el proceso de selección y distribución de contenidos curriculares en la escuela se relaciona con la pregunta que traza uno de estos textos sobre el conocimiento que se enseñará desde los parámetros de la ciencia. De allí que recurran a la perspectiva teórica de la transposición didáctica de Chevallard (1991), que sugiere reflexionar sobre la manera en que el conocimiento científico se debe transformar para poder enseñarlo, pues este se considera un modelo epistemológico del conocimiento de enseñanza. Además, se retoma la ruta planteada por Joshua y Dupin (1993) sobre la transposición analítica para potenciar este asunto, con el propósito de hacerla efectiva y que se materialice en las representaciones de los estudiantes.

En esta misma vía se cuestiona la comprensión de los conceptos básicos del cálculo en el ámbito universitario, pues encuentra una de las autoras que trabaja desde este ámbito, que al estudiar las prácticas educativas universitarias se observa una ruptura entre el aprendizaje del álgebra escolar y el cálculo diferencial en la universidad, que provoca una serie de obstáculos epistemológicos. Entre tanto, la fundamentación teórica se asienta en esta categoría de obstáculos epistemológicos desarrollada por Gastón Bachelard (2004), que hace mención a las dificultades en la comprensión de fenómenos debido a ideas previas instaladas, a conocimientos anteriores, a pensamientos propios y a creencias.

Se destaca en estas investigaciones el diseño de una ruta metodológica particular, mediante la construcción de matrices de análisis sobre la diversidad de información recopilada en el trabajo de campo, como: textos universitarios, científicos, de enseñanza formal secundaria y de los lineamientos curriculares, así como los contenidos y las prácticas de enseñanza. En consecuencia, la revisión de estos estudios resulta relevante debido a que en esta corriente se observan objetos de estudio similares al propuesto en la tesis doctoral, allí se reconoce una línea de trabajo que se ha venido desarrollando en el DIE sobre la didáctica que se sustenta en programas interinstitucionales de índole internacional. No obstante, en esta exploración se pudo identificar que la perspectiva que los orienta y la cual agencian es contraria - e incluso se opone- a la historia de las disciplinas y de los saberes escolares que sustenta esta tesis, desde donde se reconoce la singularidad del conocimiento escolar, sin que esto excluya las múltiples relaciones (tensionales, contradictorias, afines) con la epistemología de las disciplinas académicas.

\section{Del conocimiento científico y de las disciplinas académicas al conocimiento escolar y las disciplinas escolares}

Esta tercera corriente de trabajo propone reflexiones en torno a las relaciones entre el conocimiento científico, el conocimiento escolar y el conocimiento cotidiano. Así, los lugares de análisis se delinean alrededor de la epistemología que soporta la construcción de conocimiento de personas del común y de intelectuales, para hacer un contraste con el análisis de la epistemología del conocimiento escolar.

Como rasgo compartido, dichos trabajos se centran en el debate epistemológico alrededor del saber construido que circula en el ámbito escolar, con el fin de aportar a la producción de conocimientos significativos en este. Cuestionan la relación de prescripción entre el conocimiento científico y el escolar, y rechazan el supuesto de que el último queda reducido a una versión empobrecida, simplificada y falseada del primero. Por tanto, realizan una delimitación de lo que define a cada conocimiento (científico, cotidiano y escolar).

Las preguntas centrales en estas investigaciones acerca de estos tipos de conocimiento son: ¿Qué mundo se construye? ¿Para qué se construye? ¿Cuál es el criterio de validación de sus productos y cómo se construye? Así, por una parte, se propone el constructivismo diferencial con base en el presupuesto inicial de que es preciso conocer la epistemología que orienta y produce sentido en cada uno de los tipos de conocimiento ya mencionados, y el escenario de la construcción. Desde esta perspectiva, se afirma que estos tipos de conocimiento no se diferencian solo por aspectos de contenido, sino sobre todo por aspectos epistemológicos de fondo. Pero, por otro lado, se plantea la cuestión de los modelos de enseñanza/ aprendizaje de las ciencias, debido a la limitada fundamentación del enfoque de la trasposición didáctica. Al respecto, se propone la mirada constructivista del aprendizaje de las ciencias, bajo el presupuesto de transformar el conocimiento construido en el contexto escolar en un primer acercamiento a hacer ciencia.

De este núcleo y sus tres corrientes de trabajo se puede concluir que dos de las perspectivas teóricas que orientan el análisis del conocimiento del profesorado y de los alumnos son la racionalidad tecnológica y la veta psicologicista, desde las cuales este se concibe como construcciones exclusivamente cognitivas e intelectuales. Dichas perspectivas desconocen la historicidad en la construcción del conocimiento escolar, de la escuela y de los sujetos de saber que 
forman parte del sistema escolar, así como las dinámicas sociales, políticas, económicas y culturales que las caracterizan y les dan forma.

Varios de los modelos analíticos propuestos en este núcleo se pueden leer críticamente como una doxa dominante en el campo de la didáctica, que refuerza la superioridad del conocimiento científico con base en su neutralidad, su objetividad, su rigurosidad y su racionalidad frente a las disciplinas escolares (Mainer, 2009), a pesar de que en estos se reconozcan cuestionamientos al modo como se ha discutido convencionalmente la cientificidad de las ciencias sociales o su relación con la enseñanza. De acuerdo con ello, en el conjunto de investigaciones aparece la pregunta por la epistemología de las didácticas (sociales, naturales y matemáticas) como eje central en el abordaje de los diferentes objetos de estudio propuestos, lo cual podría corresponder con el imperativo de acceder al ámbito de la ciencia y gozar de reconocimiento por parte de este. En consecuencia, este posicionamiento de la didáctica, entendida como aquel conocimiento sobre "los saberes y su transmisión en los textos escolares, contribuye a marcar una diáfana frontera en el seno del campo educativo entre el trabajo de los científicos didactas y el del profesorado de a pie" (Cuesta, Mainer y Mateos, 2009, p. 36) explica que en varios de los estudios reseñados se designe a la didáctica como ciencia aplicada, encargada de normalizar y generar efectividad en las prácticas pedagógicas de los maestros.

En este sentido, el problema de investigación toma distancia de estos postulados $y$, como se ha venido señalando, se ubica en un lugar distinto de análisis, desde donde las ciencias sociales escolares se conciben como el saber producido en y para la escuela, que se convierte en materia de enseñanza, y el saber que se produce en un régimen amplio del discurso sobre la enseñanza y lo que se debe enseñar.

\section{Estatuto epistemológico de las ciencias sociales}

Este último núcleo recoge textos que ponen como centro de reflexión el estatuto epistemológico de las ciencias sociales académicas que se expresa en la cuestión del método, el objeto de estudio y en sus nominaciones, organizados en dos bloques de acuerdo con el planteamiento principal de cada uno. En el primero se ubican investigaciones que proponen esta reflexión a través del análisis de una disciplina particular de las ciencias sociales: la historia, la geografía o la sociología. En el segundo, aquellos que se aproximan a ella mediante el análisis de las ciencias sociales en su conjunto.

\section{Discusiones sobre la naturaleza de las ciencias sociales: la historia, la geografía y la sociología}

Los problemas centrales de este primer bloque giran, por un lado, alrededor del cuestionamiento a la objetividad de los estudios históricos (en relación con la interpretación de un mismo hecho histórico) y de las ciencias sociales, lo cual señalan los trabajos aquí reseñados se definirá por la perspectiva (o líneas argumentativas) con la que se aborden, por el desarrollo de las indagaciones y por las conclusiones a las que se llegue frente al objeto de estudio. A partir de esto se preguntan si es posible la verdad objetiva en la ciencia de la historia. Vinculado a ello, este tipo de trabajos promueven unos presupuestos epistemológicos y metodológicos para la disciplina histórica, retomando aspectos clave de la filosofía que tienen en cuenta la relación cognoscitiva, el proceso de conocimiento y la verdad como proceso, con el propósito de constituir una historia científica, esto es, una disciplina que propenda por conocer la verdad absoluta desde el cúmulo de verdades parciales, a través del modelo materialista-marxista (Schaff, 1974).

Por otro lado, en nexo con el anterior problema se encuentra la pregunta por la naturaleza del conocimiento historiográfico que se sustenta en la idea de carencia de consolidación ontológica de esta disciplina, lo cual pone en duda su concepción como ciencia social. En este sentido, uno de los documentos revisados propone la pregunta $¿$ es posible un conocimiento científico del hombre? Para abordarla, acude a la mirada histórica sobre la aparición de la ciencia, de la ciencia social y de la construcción del conocimiento historiográfico, en la que se retoma la distinción formulada por la filosofía moderna (mediada por los empiristas anglosajones en el siglo XVIII) entre un conocimiento común y un conocimiento natural del que se deprendería el conocimiento científico resultado de las operaciones racionales (Arostegui, 1995).

Siguiendo lo anterior, estos estudios señalan tres problemas epistemológicos al considerar la cientificidad de las ciencias sociales: no contar con maneras admisibles de observación y de experimentación, la dificultad de objetividad y la aparente limitación para formular teorías y leyes aplicables a distintos fenómenos.

Otro problema tratado se refiere a la historia de la geografía concebida como una disciplina moderna reciente y producto europeo a partir del proyecto alemán, que tiene antecedentes históricos extendidos. La 
configuración de esta disciplina, en sentido moderno, señala el estudio de referencia, es posible gracias a una ruptura epistemológica con otras formas anteriores de saber sobre el espacio que la escinde de estas (Ortega Varcarcel, 2000).

Como último problema aparece la cuestión epistemológica en la sociología desde los dilemas de la elección del objeto y el método de indagación, la función de la teoría en los métodos empíricos y la relación entre las ciencias naturales y las ciencias sociales, al igual que entre la filosofía y la sociología. De acuerdo con ello se justifica la necesidad de construir una teoría de la sociedad que se articule a los aportes de la investigación social empírica, entendida como el estudio del conocimiento de fenómenos sociales cuya base es la experiencia, sin pretender alcanzar criterios de exactitud y objetividad como en el caso de las ciencias naturales y reconociendo los aportes de reflexiones filosóficas en la construcción de conceptos, que permita distanciarse de la reproducción de los hechos y quedar atrapado por falseamientos ideológicos de los mismos (Adorno, 2001).

En este primer bloque del núcleo titulado "Estatuto epistemológico de las ciencias sociales" es recurrente la crítica a la subordinación del conocimiento social frente al de las ciencias naturales. Asimismo, en este aparece con frecuencia el cuestionamiento a los criterios de objetividad puestos en el método sin revisar la complejidad de los objetos de estudio que son trabajados en la investigación social. Por último, como rasgo común, toman marcada distancia del historicismo y del positivismo como fundamentos metodológicos y epistemológicos de las disciplinas académicas que perduraron hasta el decenio de 1930. Por el contrario, llaman la atención sobre los aportes de la teoría marxista, de la escuela de los Annales y el modelo cualitativo, que entre 1950 y 1970 renovaron el desarrollo de las disciplinas sociales y por tanto de la investigación en este campo.

\section{Discusiones sobre el conocimiento, el objeto y el método en las ciencias sociales}

En este segundo bloque se encuentran trabajos que se ocupan de cuestiones epistemológicas sobre el conocimiento social como las antes mencionadas: su carácter objetivo, sus objetos de estudio, sus métodos y su estatuto, pero analizadas desde el conjunto de las ciencias sociales. Para ello, algunos estudios centran la mirada en las discusiones entre el método científico y el método tradicional para las humanidades, dos de los enfoques de investigación preponderantes en las ciencias sociales para mediados del siglo Xx. A partir de eso, se generan apuestas como las de Habermas (1990), quien formula la crítica trascendental del lenguaje para tratar el dualismo de las ciencias, que lo lleva a la propuesta de la acción de la comunicación, concepto que hace referencia a las acciones que los sujetos realizan para establecer relaciones con el propósito de entenderse y de regular sus actividades (actos comunicativos y no comunicativos).

Otra serie trabajos producen un balance de las principales perspectivas epistemológicas en el campo de las ciencias sociales desde dichas cuestiones epistemológicas (Murillo, 2012; Palma y Pardo, 2012), en el cual señalan las contradicciones y los dilemas que problematizan el discurrir de las ciencias sociales, con el fin de restituir el sentido de su identidad y su singular cientificidad, sin desconocer su relación con las ciencias naturales.

En ellos se asume el conocimiento y la ciencia como prácticas sociales. Así, la ciencia en sentido moderno, comprendida como un tipo de conocimiento que posee un método (o métodos), que sustenta el saber que se produce y agencia, se definiría por su funcionalidad descriptiva, explicativa y en mayor medida predictiva, su pretensión de universalidad y de objetividad, su fundamentación lógica y empírica, su condición de método y su sistematicidad. De acuerdo con lo anterior, se propone la clasificación de ciencias formales (las matemáticas y la lógica) y fácticas (que se subdividen en las ciencias naturales y las sociales) desde cuatro criterios: el objeto de estudio, los métodos, el tipo de enunciados y el tipo de verdad. En este marco, se pueden observar tres modelos epocales desde los cuales históricamente se ha precisado el conocimiento científico: premoderno, moderno y actual, y se concibe en el presente.

Además, en estos se distinguen dos lugares de aparición de las ciencias sociales. Uno, en las condiciones de vida y de trabajo tanto en Europa como en América durante el siglo XIX, que permiten ver la contradicción entre la realidad efectiva propia de esta época y los ideales fomentados por el proyecto liberal que se sustentaba en la Ilustración, a lo cual se le llamó la cuestión social (Murillo, 2012). De esta forma, para regular los problemas producidos por la cuestión social se recurrió a dos tecnologías de intervención sobre los sujetos y las poblaciones en el ámbito de vida, el cuerpo y la conducta: la biopolítica y la anatomopolítica. En este contexto, las disciplinas cumplen la función de normalización y de control de las enfermedades tanto físicas (medicina) como morales (psicología), en tanto que las ciencias sociales se fundamentarían en las ciencias médicas que aparecieron en el siglo XIX. 
Otro, en el que se reconoce la transferencia al ámbito del conocimiento de la sociedad y del hombre de inquietudes, discusiones, desarrollos, entre otros, que constituyó la producción de conocimiento sobre el mundo natural de las ciencias naturales; pero también, otra matriz de localización de las ciencias sociales se identifica en el origen griego de la filosofía práctica de Aristóteles, asunto que ha sido ignorado en el ámbito de la epistemología.

Por último, los rasgos comunes y algunos de los aportes en esta corriente podrían sintetizarse en:

a. Propone un acercamiento histórico a las condiciones sociales (económicas-políticas) y de pensamiento que hicieron posible las ciencias sociales, $y$ a modelos influyentes en el conocimiento científico. Esto facilita una aproximación a la naturaleza de las ciencias sociales (sociología, historia, geografía) y a los consecuentes debates epistemológicos de cada una.

b. Ponen en discusión la perspectiva positivista en la configuración de las ciencias sociales, y su epistemología; asimismo, debaten los enfoques preponderantes que influyeron en las ciencias sociales durante los siglos XIX y XX. En consecuencia, abordan la relación entre las ciencias naturales y sociales de manera crítica, así como la cuestión sobre el estatuto científico de las ciencias sociales.

c. En relación con lo anterior, se cuestiona la hegemonía del positivismo en las formas de conocimiento propias de las ciencias sociales. Por el contrario, se muestra como objeto de estudio de estas su estatuto epistemológico y su quehacer, más que el mundo social en sí mismo.

d. Identifican tendencias o perspectivas conceptuales y epistemológicas generales de las ciencias sociales que han caracterizado la configuración de la ciencia en sentido moderno y en particular las ciencias sociales durante los siglos XIX y Xx; distinguen debates epistemológicos en sí mismos en cada una de estas posturas y advierten desafíos que se presentan a este ámbito de conocimiento.

e. Las preguntas más recurrentes se establecen alrededor de la objetividad de los estudios en las ciencias sociales, la cuestión de su verdad, el tipo de conocimiento o la naturaleza del que producen, el asunto del método, de los objetos o problemas de estudio, el lenguaje propio, la construcción de teorías en este campo y la cuestión del estatuto epistemológico.

f. Se proponen distintos tipos de problemas de carácter gnoseológico, ontológico, metodológico, epistemológico y político en torno a la delimitación de las ciencias sociales y a su producción de conocimiento.
Esto muestra la ruptura que proponen estas investigaciones entre el surgimiento de las ciencias naturales y de las ciencias sociales, desde donde se promueve la definición del estatuto epistemológico del conocimiento social, ya sea de la historia, de la sociología, de la geografía o desde su carácter articulado, para cuestionar su sujeción a la constitución epistemológica de las ciencias naturales y equiparar el proceso de surgimiento al de estas últimas. No obstante, la compulsión por establecer las discusiones epistemológicas de este campo, tal y como se señalaba en el anterior núcleo de la didáctica de las ciencias sociales, podría responder a la necesidad artificiosa de ocupar un lugar en el campo científico. Ya advertía Foucault (1993) que, aunque las ciencias del hombre se ubicaran en el intersticio del triedro de saber de la episteme moderna, en el volumen de este espacio al igual que otras ciencias como la química o las matemáticas, no son ciencia en sentido estricto. Esto significa que

[...] su positividad está enraizada en él [campo epistemológico], que allí encuentran su condición de existencia, que por tanto, no solo únicamente ilusiones, quimeras seudocientíficas, motivadas en el nivel de las opiniones, de los intereses, de las creencias, que no son lo que otros llaman, usando un nombre caprichoso, "ideología", pero, a pesar de todo, esto no quiere decir que sean ciencias [...] Así es inútil decir que "las ciencias humanas" son falsas ciencias; no son ciencias en modo alguno; la configuración que define su positividad y las enraíza en la episteme moderna las pone, al mismo tiempo, fuera del estado de ser de las ciencias. (pp. 354-355).

Así, las ciencias sociales obedecen al dominio positivo del saber. La dificultad en la incertidumbre como ciencias no reside en la complejidad de su objeto de estudio, ni en la imposibilidad de adquirir un estatuto epistemológico reconocido, ni en la limitación de su método, sino en su ubicación nebulosa, esto es, en la complejidad de la configuración epistemológica en la que se encuentran localizadas mediante la relación constante con las tres dimensiones (las ciencias matemáticas y físicas; las ciencias de la vida, el lenguaje y el trabajo; y la filosofía), lo que le permite a ese objeto ser dominio positivo del saber y no objeto de ciencia.

Finalmente, de la exploración por la constitución histórica de las disciplinas sociales en sentido moderno que se advierte en este núcleo, es posible identificar las condiciones que hicieron posible su surgimiento, por ejemplo en el caso de la geografía, que responde a la expansión colonial europea, al desarrollo del moderno nacionalismo y a su reconocimiento en el sistema educativo como campo de 
conocimiento, que permite denotar trazos en las relaciones entre las epistemologías de estas disciplinas y su constitución como conocimiento escolar, aunque como se ha anotado tiene puntos de inflexión pero también de distancia en el proceso de configuración.

\section{Conclusiones}

A lo largo del documento se presentó la revisión bibliográfica realizada en el marco de una tesis doctoral inscrita en el campo de la historia de la educación, que se soportó en la producción académica sobre las ciencias sociales escolares y sus relaciones con las epistemologías de las ciencias sociales, organizada en tres núcleos o tendencias: sociogénesis o configuración histórica de las disciplinas y de los saberes escolares; didácticas de las ciencias, su estatuto epistemológico y el conocimiento escolar; y estatuto epistemológico de las ciencias sociales. Estas tendencias muestran multiplicidad de temas, fenómenos y categorías que dan cuenta de la dispersión existente para abordar las relaciones antes mencionadas que han sido problematizadas en el estudio de referencia, aun cuando estas, en términos de complementariedad, de articulación, de tensión o de exclusión han sido un asunto problemático para el ámbito de producción de las reformas y las políticas educativas, para el académico y para docentes en sus prácticas pedagógicas.

Esta situación revela por qué desde dichos lugares muchas veces se acude a propuestas que sugieren la adaptación del conocimiento científico o académico al espacio de la enseñanza escolar, como la de la transposición didáctica planteada por Yves Chevallard (1991) principalmente para las matemáticas, consistente en modificar un contenido de saber generado en la ciencia o saber sabio para adaptarlo a su enseñanza o convertirlo en saber didactizado. Ejemplos de ello se encuentran en los debates que profesionales de las ciencias sociales y humanas, cuya trayectoria académica no se inscribe necesariamente en el ámbito de la educación, como Campos, Bonilla (2012) y Melo (2014), quienes apuestan por consolidar disciplinar y epistemológicamente la formación de maestros y actualizar los libros de texto de acuerdo con lo que se publica y se descubre en la academia.

Pero también, se llama al "pedagogismo autista" que resolverá diversos problemas en lo educativo, como la calidad, la pertenencia, la apropiación y la lectura crítica de la realidad desde los contenidos de enseñanza, entre otros, sin tener diálogo ni articulación alguna con los desarrollos y las reflexiones contemporáneas de las disciplinas académicas. Ya lo advertía José Gregorio Rodríguez (s. f.) en su análisis sobre las políticas educativas del decenio de 1990, cuando reclama el aporte de la universidad en el desarrollo de la educación señalando que "la investigación que realizan las universidades y su participación en el planeamiento regional y local se hace indispensable para no caer en la manipulación de los intereses particulares o en el pedagogismo a ultranza" (p. 220). En su argumento puede verse un llamado a la articulación entre el ámbito académico y el escolar, como dos niveles constitutivos de lo educativo.

En esta misma vía, a pesar de encontrarse escasez de estudios que aborden esta relación, o de evidenciarse la dispersión de temas en los que se hace énfasis en uno u otro ámbito, como se mostró en esta revisión bibliográfica, la doctora en Estudios Latinoamericanos Alcira Aguilera (2017) reconoce en un trabajo reciente de su autoría algunas propuestas que han intentado restituir este vínculo entre la enseñanza de las ciencias sociales y la configuración de las disciplinas sociales, lo cual fue constitutivo de ambos campos a principios del siglo xx en el país. En dicho trabajo revisa de manera crítica supuestos dados por ciertos en el campo de la enseñanza de la historia y las ciencias sociales en Colombia, que expresan contrasentidos, es decir, "enunciados que se han naturalizado en nuestra cultura académica pero que en algunos discursos y prácticas evidencian lo contrario" (p. 16). Tal es el caso del contrasentido entre las disciplinas escolares y las disciplinas sociales (científicas y/o académicas), en el que se asume una supuesta distancia entre el conocimiento propio de las últimas y el conocimiento escolar.

Así, descubre intentos en las últimas tres décadas de restaurar la fractura de este vínculo, que dan cuenta de las relaciones que ha tenido la producción en los campos disciplinares, particularmente en la historia, con los desarrollos pedagógicos y didácticos de su enseñanza, ya sea desde el análisis o la producción de textos escolares como el caso de De Roux (1985a), Kalmanovitz y Duzán (1986), de la historia oral o desde abajo de Archila (2004) o Méndez (2002), o de experiencias pedagógicas basadas en una perspectiva histórica crítica, como las de Vega (1998) o Castro (2004), así como las rutas pedagógicas del IDEP (2011) y la experiencia de la RED de la Universidad Nacional de Colombia.

De esta revisión también se puede destacar la insistencia por conceptualizar las categorías de ciencias sociales académicas y de didáctica desde el énfasis en su estatuto epistemológico, como se aprecia en dos de los niveles abordados. Esto se constata claramente en la apuesta por concebir esta última como una disciplina y un constructo teórico sobre la enseñanza; de allí que en uno de los estudios se destaquen tres 
interpretaciones vigentes sobre la naturaleza de este tipo de conocimiento: las didácticas específicas como disciplinas científicas que se sustentan en exploraciones empíricas sobre la enseñanza, que es su objeto de estudio; la didáctica como una teoría práctica; y la didáctica como el conjunto de conocimiento sostenido en distintas ciencias (Aisenberg, 1998). De esto se deriva el interés en las investigaciones que agrupan esta temática en indagar cómo se produce conocimiento didáctico, cuáles son los criterios de validez y cuál es su naturaleza. Esto se expresa en la reiteración por modelos de análisis para trabajar los textos de educación formal secundaria, los textos científicos o los lineamientos curriculares, bien sea desde la transposición didáctica, como en la propuesta del constructivismo diferencial de Rodrigo (1994) y de Gil (1994), o en el programa científico de la didáctica centrada en significados según la propuesta de Camilloni (1995); y claramente en Bermúdez y De Longui (2012) y Martínez y Rivero (2012), que en todo caso expresan una idea dominante en el campo de la didáctica como lo ha expresado Mainer (2009). Este autor defiende el carácter objetivo y privilegiado del conocimiento científico, como referencia fundamental de las disciplinas escolares, a pesar de que en varias de ellas se propongan interrogantes a la manera como tradicionalmente se ha asumido la cuestión de la cientificidad de las ciencias sociales o su relación con la enseñanza, desde por ejemplo el "aplicacionismo disciplinar" al que hace mención Aisenberg (1998), o el reconocimiento de la existencia del conocimiento escolar que aparece en Rodrigo (1994) y en Gil (1994), o del conocimiento específico que se produce en la didáctica que advierten Camilloni (1995), Benejam (1997), Aisenberg (1998), Martínez y Rivero (2012), Bermúdez y De Longuí (2012), y Neira (2012).

De la misma manera, en el último núcleo se recurre constantemente a la pregunta por la naturaleza del conocimiento de las ciencias sociales, a su objetividad y a su rigurosidad metódica, como se constata en Schaff (1974), en Habermas (1990), en Aróstegui (1995), en Adorno (2001) y en Ortega Valcárcel (2000), por lo que la cuestión del estatuto epistemológico, el objeto de estudio y el método, se establecen en los focos de problematización de cada una de ellas.

Por su parte, en el primer núcleo de estudios referido a la sociogénesis de las disciplinas escolares se aprecia una conceptualización distinta sobre didáctica que se concibe crítica por interrogar de manera racional y consciente los mecanismos y las estrategias de dominación que se efectúan en la escuela; en últimas por constituirse en una crítica radical de la cultura, sin volcarse en un conocimiento especializado en función de esta dominación. Ello conduce a

... Una didáctica de la crítica, de la sospecha, pero también de la escucha [...] -desde la idea de la problematización del presente que se liga a una concepción genealógica de los problemas sociales que nos acucian y, por tanto, a la necesidad de servirse del "mejor" conocimiento disponible en ese empeño, o la idea de impugnar los códigos pedagógicos y profesionales dominantes-, y con la racionalidad comunicativa -la idea del diálogo no sólo como vehículo de informaciones y contraste de pareceres sino también, y sobre todo, como inagotable fuentes de deseos y conocimientos compartidos. (Mainer, 2001, pp. 15-16).

Eso da cuenta de su encuadre en una teoría crítica de la educación. Asimismo, resultado de los aportes de este núcleo se empieza a conceptualizar en la tesis doctoral las ciencias sociales escolares como aquel saber producido en la escuela y que corresponde a los fines de esta, que se vuelve asignatura y contenidos de enseñanza, pero también el saber que es producido tanto en el nivel de la macropolítica como en uno intermedio, que muchas veces alude al ámbito académico, sobre la enseñanza. Dicho saber se establece a partir de la regulación de la enseñanza (administración de materias, de horarios, de asignación por niveles y de extensión en el pensum), de los contenidos (desde el nivel estratégico mediante los planes y programas oficiales de enseñanza primaria y secundaria) y de las prácticas regladas.

Como conclusión podría afirmarse que esta insistencia por lo epistemológico bien sea en el campo de la didáctica de las ciencias o de las ciencias sociales académicas muestra una supremacía del conocimiento científico sobre el conocimiento escolar. Esto favorece el bosquejo de sendas fronteras en el campo educativo entre el trabajo de los científicos sociales y el del profesorado (Cuesta, Mainer y Mateos, 2009); asunto que claramente ha sido problematizado en la investigación que sustenta esta revisión.

\section{Referencias}

Adorno, T. (2001). Epistemología y ciencias sociales (trad. Vicente Gómez). Colección Frónesis. Madrid: Cátedra.

Aguilera, A. (2017). La enseñanza de la historia y las ciencias sociales hoy: contrasentidos y posibilidades. Folios, 46, 15-27.

Aisenberg, B. (1998). Didáctica de las ciencias sociales: ¿Desde qué teorías estudiamos la enseñanza? Teoría y didáctica de las ciencias sociales, 3(98), 136-163. 
Alderoqui, S. y Aisenberg, B. (coord.) (1994). Didáctica de las ciencias sociales: aportes y reflexiones. Madrid: Paidós Ibérica.

Alderoqui, S. y Aisenberg, B. (coord.) (1998). Didáctica de las ciencias sociales II: teorías con prácticas. Madrid: Paidós Ibérica.

Álvarez, A (2007). Formación de nación y educación. Bogotá: Siglo del Hombre, Grupo Historia de la Práctica Pedagógica.

Álvarez, A. (2010). Las ciencias sociales en el currículo escolar: Colombia 1930-1960. Madrid: Departamento de Historia de la Educación y Educación Comparada, Facultad de Educación, Universidad Nacional de Educación a Distancia. Versión digitalizada.

Archila, M. (2004). El historiador y la enseñanza de la historia. En J. G. Rodríguez, Rutas pedagógicas de la historia en la educación básica de Bogotá. Bogotá: REDUniversidad Nacional de Colombia.

Aróstegui, J. (1995). La investigación histórica: teoría y método. Barcelona: Grijalbo Mondadori.

Bachelard, G. (1938/2004). La formación del espíritu científico (trad. José Barbini). México: Siglo xxI.

Benejam, P. (1997). Las finalidades de la educación social. En P. Benejam, J. Pagés, P. Comes y D. Quinquerc. Enseñary aprender ciencias sociales, geografía e historia en la educación secundaria. Barcelona: Horsori.

Benejam, P. y Pagès, J. (coord.) (1997). Enseñar y aprender ciencias sociales, geografía e historia en la educación secundaria. Barcelona: Horsori, Universitat de Barcelona, Instituto de Ciencias de la Educación.

Bermúdez, G. y De Longhi, A. (2012). Análisis de la transposición didáctica del concepto de biodiversidad. Orientaciones para su enseñanza. En A. Molina, Algunas aproximaciones a la investigación en educación en enseñanza de las ciencias naturales en América Latina. Bogotá: Doctorado Interinstitucional en EducaciónUniversidad Distrital Francisco José de Caldas.

Camilloni, A. (1995). Epistemología de la didáctica de las ciencias sociales. En B. Aisenberg y Alderoqui, S. (comp.), Didáctica de las ciencias sociales. Aportes y reflexiones. Madrid: Paidós Ibérica.

Capel, H. (1987). Geografía humana y ciencias sociales: una perspectiva histórica. Barcelona: Montesinos.

Castro, F. (2004). Los proyectos de investigación histórica escolar. Educación y Cultura, 65, 68-75.

Chervel, A. (1991). Historia de las disciplinas escolares. Reflexiones sobre un campo de investigación. Revista de Educación, 295, 59-111.
Chevallard, Y. (1991). La transposición didáctica. Del saber sabio al saber enseñado. Buenos Aires: Aique.

Chorley, R. y Haggett, P. (1971). La geografía y los modelos socioeconómicos (trad. Carlos Ferrán Alfaro). Madrid: Nuestro Tiempo.

Cuesta, R. (1997). Sociogénesis de una disciplinar escolar: la Historia. Barcelona: Pomares-Corredor.

Cuesta, R. (2008). Los deberes de la memoria en la educación. Barcelona: Octaedro.

Cuesta, R., Mainer, J. y Mateos, J. (2009). Modos de educación y problemas de periodización histórica desde una perspectiva genealógica. En Transiciones, cambios y modos de educación (pp. 19-82). Salamanca: Nebraska.

De Roux, R. (1985a). Nuestra historia. Historia cercana 5. Bogotá: Estudio.

De Roux, R. (1985b). A propósito de la historia que se enseña a los niños. Educación y Cultura. Bogotá: FECODE.

Foucault, M. (1966/1993). Las palabras y las cosas (trad. Elsa Cecilia Frost). México: Siglo XxI.

Gil, D. (1994). Relaciones entre conocimiento escolar y conocimiento científico. Investigación en la Escuela, 23, 17-31.

Goodson, I. (1991). La construcción social del currículum. Posibilidades y ámbitos de investigación de la historia del currículum. Revista de Educación, 295, 7-37.

Goodson, I. (2003). Estudio del currículum. Casosy métodos. Buenos Aires: Amorrortu.

Goodson, I. (comp.) (1995). Historia del currículum. La construcción social de las disciplinas escolares. (trad. Joseph M. Apfelbäume). Barcelona: Pomares-Corredor.

Gordon, S. (1995). Historia y filosofía de las ciencias sociales. Barcelona: Ariel.

Habermas, J. (1990). La lógica de las ciencias sociales. Madrid: Tecnos.

Hirst, P. (1982). Educación y desarrollo de la razón: formación del sentido crítico (trad. Guillermo Solana y Víctor Peña), Madrid: Narcea.

Jiménez, A. y Torres, A. (2006). La construcción del problema de investigación y los referentes teóricos. En A. Jiménez y A. Torres (comp.), La práctica investigativa en ciencias sociales. Bogotá: Universidad Pedagógica Nacional.

Joshua, S. y Dupin, J. (1993). Introduction á la didactique des sciences et des mathématiques. París: PUF.

Kalmanovitz, S. y Duzán, S. (1986). Historia de Colombia Grado 9. Bogotá: El Cid. 
Mainer, J. (2007). Sociogénesis de la didáctica de las ciencias sociales. Tradición discursiva y campo profesional (1900-1970) (tesis doctoral). Universidad de Zaragoza, España.

Mainer, J. (2009). La forja de un campo profesional. Pedagogía y didáctica de las ciencias sociales (1900-1970). Madrid: Consejo Superior de Investigaciones Científicas.

Mainer, J. (2010). La historia de las disciplinas escolares. Génesis y problemas de un joven campo de investigación. Bogotá: Universidad Distrital Francisco José de Caldas. [Versión en línea http://www.nebraskaria.es/ Nebraskaria/Trabajos_y_publicaciones_files/La\%20 historia\%20delas\%20disciplinas\%20....pdf].

Mainer, J. (coord.) (2001). Discursos y prácticas para una didáctica crítica. Ideas y líneas de trabajo para transformar la enseñanza. Sevilla: Díada.

Mainer, J. (coord.) (2008). Pensar críticamente la educación escolar. Perspectivas y controversias historiográficas. Zaragoza: Universidad de Zaragoza.

Martínez, C. (2000). Las propuestas curriculares sobre el conocimiento escolar en el área de conocimiento del medio: dos estudios de caso en profesores de primaria (tesis doctoral). Programa Didáctica de las Ciencias Experimentales y Sociales, un enfoque interdisciplinar. Sevilla: Universidad de Sevilla.

Martínez, C. y Rivero, A. (2012). La investigación sobre el conocimiento profesional del profesor: algunos aspectos conceptuales y metodológicos. En A. Molina, Algunas aproximaciones a la investigación en educación en enseñanza de las ciencias naturales en América Latina. Bogotá: Doctorado Interinstitucional en EducaciónUniversidad Distrital Francisco José de Caldas.

Mateos, J. (2008). La construcción del código pedagógico del entorno. Genealogía de un saber escolar (tesis doctoral). Universidad de Salamanca, España.

Melo, J. (2014, 26 de agosto). El fin de la historia. El Tiempo. Recuperado de http://www.jorgeorlandomelo.com/ ti_elfin.html

Méndez, I. (2002). Hacia una didáctica de la historia: análisis de las propuestas de enseñanza de la historia que se publicaron durante la última década del siglo XX (tesis inédita de pregrado). Bogotá: Universidad Pedagógica Nacional.

Moore, T. (1980). Introducción a la teoría de la educación. Madrid: Alianza.

Murillo, S. (2012). Prácticas científicas y procesos sociales. Una genealogía de las relaciones entre ciencias naturales, ciencias sociales y tecnologías. Buenos Aires: Biblos.
Neira, G. (2012). Del álgebra al cálculo: ¿transición o ruptura? Notas para una reflexión epistemológica y didáctica. En O. León (comp.), Pensamiento, epistemología y lenguaje matemático. Bogotá: Doctorado Interinstitucional en Educación-Universidad Distrital Francisco José de Caldas.

Ortega, J. (2000). Los horizontes de la geografía. Teoría de la geografía. Barcelona: Ariel.

Palma, H. y Pardo, R. (2012). Epistemología de las ciencias sociales. Perspectivas y problemas de las representaciones científicas de lo social. Buenos Aires: Biblos.

Popkewitz, Th. (1987). La producción del conocimiento escolar y los lenguajes curriculares. Cuestiones institucionales en el seguimiento de las matemáticas escolares. Revista de Educación, 282, 61-84.

Roa, G. (2017). El pedagogismo y la fragmentación de las humanidades. Santo Domingo. Recuperado de http:// almomento.net/el-pedagogismo-y-la-fragmentacionde-las-humanidades/

Rodrigo, M. (1994). El hombre de la calle, el científico y el alumno: ¿un solo constructivismo o tres? En Investigación en la Escuela, 23, 7-16.

Rodríguez, J. (s. f.) La política educativa en la década de los 90: ¿camino de modernidad o instrumento de modernización? (213-222). Recuperado de http://www. bdigital.unal.edu.co/1441/8/07CAPI06.pdf

Schaff, A. (1974). Historia y verdad (trad. Ignasi Vidal Sanfeliu). México: Grijalbo.

Semana (24 de marzo de 2012). La crisis de la historia. Bogotá: Semana. Recuperado de http://www.semana. com/nacion/articulo/la-crisis-historia/255378-3

Silva, O. (2012). Historia de las disciplinas y de los saberes escolares: un campo de investigación emergente en Colombia. Ponencia presentada en el VI Seminario Taller Internacional Vendimia. Villa de Leyva: Rudecolombia.

Silva, O. (2017). Consolidación y configuración de la enseñanza de las ciencias sociales como campo de saber-poder en Colombia 1976-1994 (tesis doctoral). Universidad Distrital Francisco José de Caldas.

Silva, O. (2018). Investigar históricamente las disciplinas y los saberes escolares: el caso de la enseñanza de las ciencias sociales en Colombia. Pedagogía y Saberes, 49, p. 81-93.

Vega, R. (1998). La historia oral, enseñanza de la historia y conocimiento. Bogotá: Anthropos.

Viñao, A. (1995). Historia de la educación e historia cultural: posibilidades, problemas y cuestiones. Revista de Educación, 306, 245-269. 
Viñao, A. (2002). Sistemas educativos, culturas escolares y reformas: continuidades y cambios [versión en línea]. Recuperado de http://www.oei.org.ar/edumedia/ pdfs/T05_Docu3_Sistemaseducativosculturasescolares_Vinao.pdf

Viñao, A. (2006). La historia de las disciplinas escolares. Historia de la educación, 25, 243-269.
Viñao, A. (2009). Modos de educación y problemas de periodización histórica. Comentarios y observaciones. En Transiciones, cambios y modos de educación. Nebraska: Salamanca (pp. 19-82).

Walford, R., Bale, J. y Graves, N. (eds.) (1973). Perspectives in Geographical Education. Edinburgh: Oliver y Boyd. 


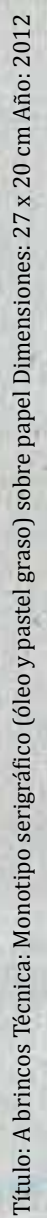
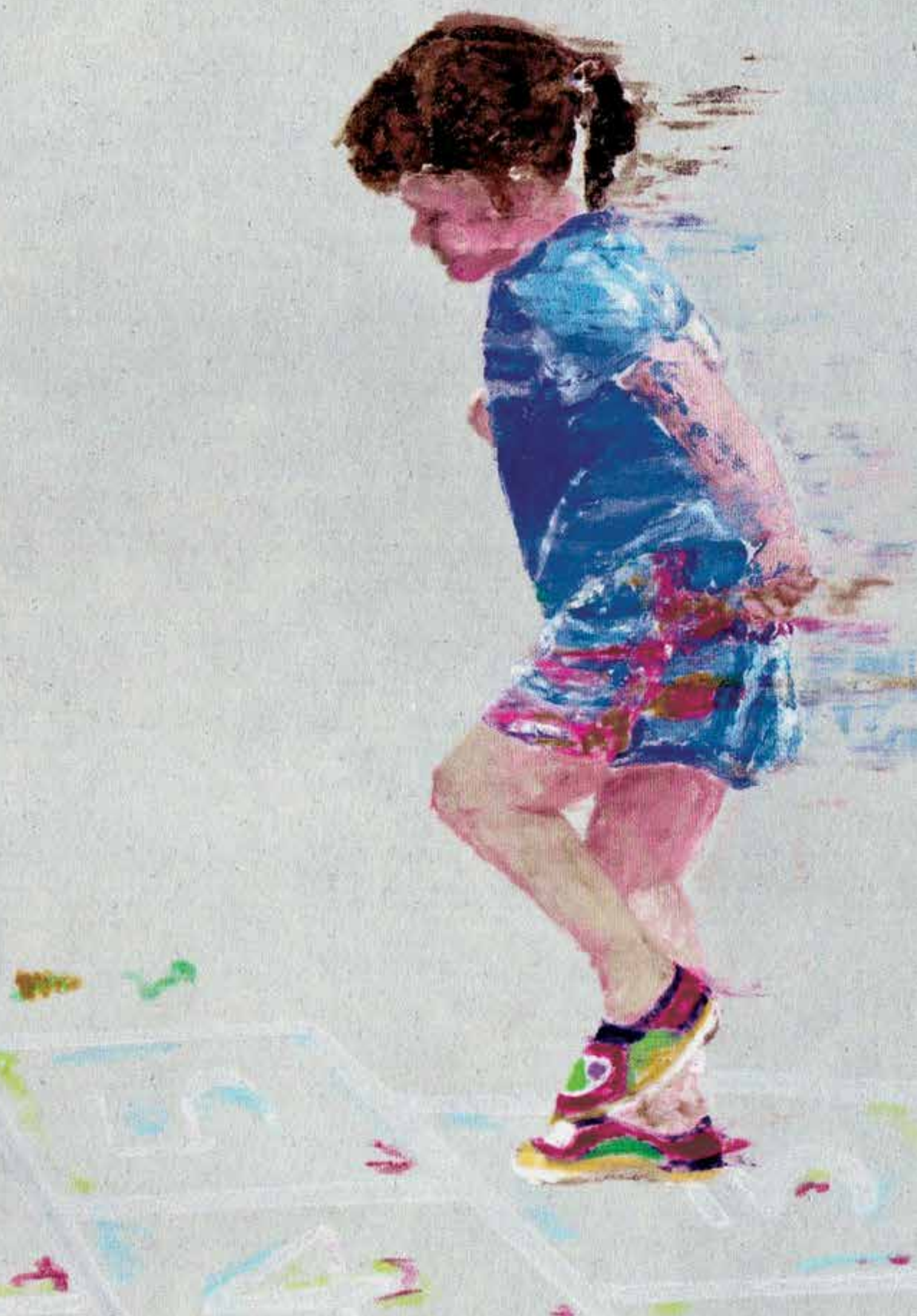